\title{
Developmental Dysplasia of the Hip
}

\section{Editorial Comment}

\author{
Muharrem Inan MD, Feza Korkusuz MD
}

(C) The Association of Bone and Joint Surgeons 2008

Hippocrates (400 BC) first described atraumatic hip dislocations in children in his books "Instruments of Reduction" and "On Articulations," and provided guidelines for diagnosis and treatment. Throughout most of recent history the entity was called, "congenital dislocation of the hip," although within the past decade "developmental dysplasia of the hip" (or DDH) has become the preferred term. Early diagnosis and treatment of DDH is a major issue of health care providers, including pediatricians and orthopaedic surgeons. Late diagnosis results in more complex treatments with higher rates of failures and complications. Late diagnosis also may lead to disabling osteoarthritis in adulthood. It is therefore well accepted that all newborn infants should be carefully screened for DDH, not only those with risk factors. Physical examination using the Ortolani [5] and Barlow [2] maneuvers is most widely used to diagnose newborn DDH. However, late-diagnosed or late-onset hip dislocations needing treatment are not rare and screening guidelines need to be adjusted to diagnose these patients. Static and dynamic ultrasound screening popularized by Graff [3] and Harcke et al. [4] are wellaccepted diagnostic tools that add valuable information to the physical examination and are considered the "gold standard" for diagnosis in some countries. However, ultrasound evaluation of the hips has not been universally adapted even in the industrialized world and in developing countries is not widely available. Therefore, there is still a

M. Inan $(\bowtie)$

Medical Faculty, Orthopaedic Department, Yeditepe University

Hospital, Kozyatagi, İstanbul 44039, Turkey

e-mail: minan@yeditepe.edu.tr

F. Korkusuz

Department of Physical Education and Sports, and Medical Center, Middle East Technical University, Ankara, Turkey place for simple, effective, and inexpensive methods to allow early diagnosis.

In this symposium a series of articles systematically addresses various aspects of diagnosis and current treatment strategies. Orthopaedic surgeons should rely on Pavlik harness [1] treatment in early diagnosed patients. If unsuccessful, closed and/or open reduction and casting should be carried out by experienced pediatric orthopaedic surgeons. Several open reduction techniques are described as well as some of the differing types of pelvic osteotomies. Unsuccessful surgical attempts will most likely lead to substantial morbidity in the future life of the patient. Debate on techniques used to obtain concentric reduction and facilitate optimal hip development, or to prevent late osteoarthritis, will continue in the foreseeable future. Therefore future studies will need to demonstrate which techniques offer substantial and which offer only marginal benefits and which will be universally applicable in all countries. Only longer-term followup studies of these treatments will allow an accurate assessment of a reduction in the risk of secondary adult osteoarthritis.

The guest editors are indebted to the contributing authors and to Dr. Richard Brand, who guided the processing of this symposium.

\section{References}

1. Arnold P. Die funktionelle Behandlungsmethode mittels Riembenbhgel als Prinzip der konservativen Therapie bei angeborenen hüftgelenksverrenkungen der Süuglinge. Zeitschr. $f$. Orthop. 1957;89:341-352.

2. Barlow TG. Early diagnosis and treatment of congenital dislocation of the hip. J. Bone and Joint Surg Br. 1962;44:292-301.

3. Graf R. The diagnosis of congenital hip-joint dislocation by the ultrasonic Combound treatment. Arch Orthop Trauma Surg. 1980;97:117-133. 
4. Harcke HT, Clarke NM, Lee MS, Borns PF, MacEwen GD. Examination of the infant hip with real-time ultrasonography. J Ultrasound Med. 1984;3:131-137.
5. Ortolani M. The classic. Congenital hip dysplasia in the light of early and very early diagnosis. Clin Orthop Relat Res. 1976; 119:6-10. 